\title{
Dyspnoea: a multidimensional and multidisciplinary approach
}

\author{
Louis Laviolette ${ }^{1,2,3,7}$ and Pierantonio Laveneziana ${ }^{1,2,4,5,7}$, on behalf of the ERS \\ Research Seminar Faculty ${ }^{6}$
}

\begin{abstract}
Affiliations: 'Sorbonne Universités, UPMC Univ Paris 06, UMR_S 1158, Neurophysiologie Respiratoire Expérimentale et Clinique, F-75005, Paris, ${ }^{2}$ INSERM, UMR_S 1158, Neurophysiologie Respiratoire Expérimentale et Clinique, F-75005, Paris, ${ }^{4} \mathrm{AP}-\mathrm{HP}$, Groupe Hospitalier Pitié-Salpêtrière Charles Foix, Service des Explorations Fonctionnelles de la Respiration, de l'Exercice et de la Dyspnée, F-75013, Paris, and ${ }^{5}$ Service d'Explorations Fonctionnelles Respiratoires, Centre de Référence de l'Hypertension Pulmonaire Sévère, DHU TORINO "Thorax Innovation", INSERM U999, LabEx LERMIT, "Hypertension Artérielle Pulmonaire, Physiopathologie et Innovation thérapeutique", Hôpital Universitaire de Bicêtre (AP-HP), Univ Paris-Sud 11, Le Kremlin-Bicêtre, France. ${ }^{3}$ Centre de Recherche clinique de l'Institut Universitaire de Cardiologie et Pneumologie de Québec (CRIUCPQ), Québec, QC, Canada. ${ }^{6} \mathrm{~A}$ full list of members of the ERS Research Seminar Faculty can be found in the Acknowledgements section. ${ }^{7} \mathrm{~L}$. Laviolette and P. Laveneziana have contributed equally and are both first authors.
\end{abstract}

Correspondence: P. Laveneziana, AP-HP, Groupe Hospitalier Pitié-Salpêtrière Charles Foix, Service des Explorations Fonctionnelles de la Respiration, de l'Exercice et de la Dyspnée, 47-83 Boulevard de l'Hôpital, 75013, Paris, France. E-mail: pierantonio.lavenezianalapsl.aphp.fr

ABSTRACT Dyspnoea is a debilitating symptom that affects quality of life, exercise tolerance and mortality in various disease conditions/states. In patients with chronic obstructive pulmonary disease (COPD), it has been shown to be a better predictor of mortality than forced expiratory volume in $1 \mathrm{~s}$. In patients with heart disease it is a better predictor of mortality than angina. Dyspnoea is also associated with decreased functional status and worse psychological health in older individuals living at home. It also contributes to the low adherence to exercise training programmes in sedentary adults and in COPD patients. The mechanisms of dyspnoea are still unclear. Recent studies have emphasised the multidimensional nature of dyspnoea in the sensory-perceptual (intensity and quality), affective distress and impact domains. The perception of dyspnoea involves a complex chain of events that depend on varying cortical integration of several afferent/efferent signals and coloured by affective processing. This review, which stems from the European Respiratory Society research symposium held in Paris, France in November 2012, aims to provide state-of-the-art advances on the multidimensional and multidisciplinary aspects of dyspnoea, by addressing three different themes: 1) the neurophysiology of dyspnoea, 2) exercise and dyspnoea, and 3) the clinical impact and management of dyspnoea.

@ERSpublications

ERS research faculty emphasises the need to translate new understanding of dyspnoea mechanisms into better treatment http://ow.ly/sxpFG

This article has supplementary material available from www.erj.ersjournals.com

Received: May 312013 | Accepted after revision: Dec 122013 | First published online: Feb 132014

Support statement: The research seminar was sponsored by the European Respiratory Society with the financial support of unrestricted grants from Boehringer-Ingelheim (International), Cosmed (Italy) and ADinstruments (France). L. Laviolette was supported by the Institut Universitaire de Cardiologie et Pneumologie de Quebec (IUCPQ) foundation, Quebec, QC, Canada (2010-2011; 2013); a long-term research fellowship from the European Respiratory Society (LTRF fellowship no. 39-2011; 2011-2012); and a post-doctoral research fellowship from the Fond de la Recherche en Santé du Quebec (FRSQ, 2012-2013).

Conflict of interest: Disclosures can be found alongside the online version of this article at www.erj.ersjournals.com

Copyright @ERS 2014 


\section{Introduction}

On November 8-9, 2012 in Paris, France, some of the foremost experts on the topic of dyspnoea came together to discuss this important symptom and extend its boundaries as a target of interest in clinical practice and research. This European Respiratory Society (ERS) research symposium was organised by the ERS Scientific Committee and the ERS group 4.01 (full programme in online supplement, along with a link to the dedicated ERS website for speakers contributions). This review will briefly sum up the different topics of discussion. It is important to consider that this paper does not address all aspects of dyspnoea, as recently outlined by the updated American Thoracic Society (ATS) statement on dyspnoea, but focuses on three specific themes: 1) neurophysiology of dyspnoea, 2) exercise and dyspnoea, and 3) clinical management of dyspnoea.

Dyspnoea can be defined as "a subjective experience of breathing discomfort that consists of qualitatively distinct sensations that vary in intensity" $[1,2]$. It is a debilitating symptom, whose impact is second only to that of pain; it is estimated that up to a quarter of the general population and half of severely ill patients are affected by it [3-7]. Dyspnoea is also an important predictor of quality of life, exercise tolerance and mortality in various conditions. In patients with chronic obstructive pulmonary disease (COPD), it has been shown to be a better predictor of mortality than forced expiratory volume in $1 \mathrm{~s}$ (FEV1) [8]. In patients with heart disease referred for clinical exercise testing, it is a better predictor of mortality than angina [9]. Dyspnoea is also associated with decreased functional status and worse psychological health in older individuals living at home [10]. It is also a factor in the low adherence to exercise training programmes in sedentary adults [11] and in patients with COPD [12].

The recent ATS statement has emphasised the multidimensional nature of dyspnoea in the sensoryperceptual (intensity and quality), affective distress and impact domains [2]. The perception of dyspnoea involves a complex chain of events that depend on varying cortical integration of several afferent/efferent signals and coloured by affective processing. The aim of this ERS research symposium was to provide stateof-the-art advances on the multidimensional and multidisciplinary aspects of dyspnoea, by addressing three different themes: 1) the neurophysiology of dyspnoea, 2) exercise and dyspnoea, and 3) the clinical impact and management of dyspnoea.

\section{The neurophysiology of dyspnoea}

Breathing is usually unconscious, even if cortically mediated processes modify its automatic, medullary rhythm constantly. This is thought to be similar to the unconscious processing of all the various sensory information constantly detected by the sensory receptors that does not automatically reach consciousness. This "filtering system" is part of the sensory gating process $[13,14]$ that prevents the central nervous system from being constantly flooded by irrelevant sensory information. With regards to breathing, humans have the voluntary capacity to bring it into awareness at any moment or breathing may come to conscious awareness automatically if it needs to be attended to (gate-in). This gating process (gating-in or gating-out) is at the basis of monitoring essential physiological functions and adopting appropriate behaviour [15]. Thus, it has been proposed that respiratory sensations are the result of neural gating into the cerebral cortex of respiratory afferent input eliciting a somatosensory cognitive awareness of breathing and an affective response [15]. Therefore, dyspnoea may result from: 1) a discriminative process that identifies relevant afferent information on respiratory disruption/abnormalities and brings them to consciousness (sensory components: intensity and quality); and 2) affective processing that labels the now conscious sensation as unpleasant or threatening, i.e. dyspnoea [15].

As such, not all conscious breathing sensations can be labelled as dyspnoea.

The discriminative process is a modality-specific activation of cortical neural processing that depends on a change in neural activity leading to cognitive awareness. Different afferent information may therefore yield different sensations. Dyspnoea is therefore not a single sensation; there are several distinct sensations of dyspnoea, most notably: 1) work/effort ("breathing takes work or effort"); 2) tightness ("chest is constricted, chest feels tight"); and 3) air hunger ("unsatisfied inspiration, starved for air, urge to breathe, like breath holding") [2, 16-18].

For the moment, it is generally accepted that these sensations may originate from differing physiological mechanisms. For example, current theories suggest that "air hunger" may derive from increased stimulation of brainstem respiratory centres (e.g. by carbon dioxide, hypoxia or exercise) that is not matched by an adequate ventilatory response, while "work/effort" probably derives from respiratory muscle afferents and the awareness of outgoing voluntary motor command, i.e. corollary discharge $[19,20]$. Scientific evidence also supports that some of these sensations, air hunger and work/effort at least, can exist in parallel and vary independently [21]. However, it is not clear how many different types of dyspnoea exist and if their differences are mechanistic (i.e. they are subjective manifestations of different neurophysiological 
mechanisms) or semantic (i.e. the same neurophysiological mechanisms may be expressed differently in relation to age, social and cultural context, etc.). For example, when exposed to carbon dioxide or exercise without the capacity to ventilate satisfactorily, naïve subjects may choose several descriptors to describe their experience [2] and patients with cardiopulmonary diseases may choose one over another [17, 22, 23]. As such, additional research will be important to differentiate the physiological from the semantic components of dyspnoea.

In addition to sensory qualities and intensity, respiratory sensations incorporate affective dimensions, which can vary independently with the former [24]. The affective processing of respiratory sensations is thought to involve a cortical pathway or pathways parallel to respiratory somatosensation; the responses are related to the type and quality of the respiratory afferent stimuli [15]. The affective processing responsible for the unpleasantness qualities implies the activation of limbic cortical structures for air hunger and work/effort [25-29]. Affective activation by respiratory stimuli can evoke distress and motivate cognitive behaviour. As such, air hunger and work/effort do not convey the same unpleasantness or emotional content: air hunger is usually associated with greater unpleasantness and emotional response than work/effort [24].

The affective components of dyspnoea have been described by LANSING et al. [18] in a two-stage model where an immediate unpleasantness leads to withdrawal, and an emotional component leads to long-term adaptations (i.e. lifestyle changes). This model posits strong interactions between the perceptual, short-term and long-term affective responses. In experimental settings, for a given level of ventilation, the perceptual dimension of the respiratory sensation is higher than its associated emotional distress [30]. However, a study in healthy subjects suggests that when the respiratory stimulation is incremental, as with increasing inspiratory loads, unpleasantness may increase faster than perceived intensity [31]. These findings parallel results in asthmatic patient, in whom rating of unpleasantness of respiratory sensations were larger that sensory intensity [32]. Other results also support an important role for the environment in the unpleasantness associated with respiratory sensations. Results show that positive affect is associated with lower levels of breathlessness [33] while negative affect is associated with greater levels of breathlessness [34]; these observations are present in both healthy individuals and asthmatic patients [35]. In fact, affective processing reduces respiratory-related evoked potentials, potentially by means of reducing attentional resources available for processing respiration [36]. These manipulations of emotional states seem to influence the unpleasantness, rather that the intensity of perceived sensations [33]; the same holds for effects of attentional distraction [37].

These interactions between affective state and the perception of dyspnoea can be observed in patients with respiratory diseases. High anxiety/depression patients perceived increased dyspnoea [38-41] and may be associated with worst prognosis [42], while dyspnoea can cause increased anxiety and depression [43, 44]. Unpleasant respiratory sensations can therefore be associated with significant psychological suffering (anxiety and depression), which in turn have a significant impact on daily functioning, treatment adherence, hospitalisation and mortality. In fact, compared to aged-matched controls, the prevalence of anxiety and depression is increased in patients with asthma [45, 46] and COPD [47], while remaining largely undiagnosed and undertreated. In COPD patients, anxiety and depression seem to be correlated with disease severity, health status, exacerbations and hospitalisations [47, 48].

Dyspnoea is a subjective experience and its precise measurement poses a significant challenge. On dyspnoea, COMroe [49] wrote, more than 60 years ago: “...the patient's description of respiratory distress is channelled by most physicians into two terms: 'dyspnoea' and 'shortness of breath.' More precise recording of the patient's own characterization of his difficulties in breathing might lead to better correlation of these with objective tests of pulmonary function or with mechanisms responsible for the dyspnoea." Dyspnoea is a symptom label that is convenient for communication among healthcare workers, but it may obscure patients' attempts to describe what their breathing feels like and how it makes them feel [22].

Like descriptors of pain [50], those used for dyspnoeic experience show substantial variability in regards to cultural and linguistic features. Paradoxically, the language of dyspnoea also shows some consistency in at least some characterisations. Available questionnaires for measuring respiratory sensations show a large variability in their development in terms of study population (healthy or patients or both), the homogeneity of the study population (whether all participants have the same diagnosis or any of several diagnoses), study background (experimental or clinical), the nature of the rating task (quantitative or qualitative, in one's own words or according to a list of descriptors, and the nature of the available descriptors, i.e. sensory or affective) and the data analysis methods. Several questionnaires have been developed over the years to evaluate dyspnoea sensory quality, including SIMON et al. [51, 52]'s descriptors and modifications thereof $[23,53,54]$. More recently, instruments such as the Multidimensional Dyspnoea Profile (MDP) [24, 55, 56] and the Dyspnoea-12 $[57,58]$ have incorporated intensity ratings for sensory quality and affective descriptors. 
The results from several studies in healthy individuals $[52,59,60]$ and cardiopulmonary patients $[23,51$, 53-56, 58-61] reveal that patients with cardiopulmonary disease are capable of discriminating among different sensory and affective breathing descriptors, and that there are differences between patients and healthy individuals. However, the language of dyspnoea may not be sufficiently specific for differential diagnosis [61]. In light of these observations, psychometric measures of dyspnoea need to replicate findings using more than just exploratory statistical methods, more studies in languages other than English and also to balance disease-specific relevance with cross-disease comparison.

\section{Exercise and dyspnoea}

During exercise, breathing is tightly coupled to muscular and cardiovascular demands [62]. In healthy, nonathletic subjects, exercise is more of a challenge to the cardiovascular and locomotor muscle systems than the respiratory system [63]. Healthy subjects, therefore, usually report limb muscle fatigue [64, 65] as the primary cause for exercise cessation, although high level athletes may encounter respiratory limitation to exercise performance [63]. Dyspnoea in healthy humans increases in proportion to increasing ventilation and respiratory contractile effort, the later measured as the ratio of tidal oesophageal pressure swing relative to maximal pressure. Healthy young adults at the symptom-limited peak of exercise generally rate dyspnoea intensity as "moderate" [17, 64] or "severe" [66] and describe a heightened sense of effort, "work" or "heaviness" of breathing [52]. Such sensations are not usually perceived as threatening in this population because they represent, based on learning and experience, the anticipated ventilatory response to heavy exercise. These findings may, however, depend on the testing modality and protocol; cycling exercise may put more emphasis on leg muscles while running may induce higher levels of respiratory discomfort [67]. In addition, testing protocols have varying guidelines (pedalling rate, permission to stop, etc.) that may affect cardiorespiratory and symptomatic response. The current accepted theory is that dyspnoea results from a conscious awareness of the dissociation between what the brain expects and what it receives in terms of afferent information from receptors in the respiratory muscles, lungs, airways and chest wall. This feedback from peripheral sensory afferents may enable the brain to assess the effectiveness of the motor output to the respiratory muscles. When the mechanical/muscular response of the respiratory system is appropriate for the prevailing level of central respiratory motor drive then dyspnoea intensity increases in direct proportion to the level of drive and is described as a heightened sense of effort, work or heaviness of breathing [68].

Exercise not only elicits respiratory discomfort, but also limb muscle discomfort and general exertion. As a whole, the perception of physical exertion during exercise is the conscious sensation of how hard, heavy and strenuous a physical task is [69]. In exercise physiology, it is widely assumed that this conscious sensation is generated by central processing of sensory stimuli coming from skeletal muscles, heart and lungs (afferent feedback model) [70]. However, this assumption is based on philosophical arguments and correlative evidence, and it does not fit with available experimental evidence. In fact, studies in which afferent feedback during exercise has been reduced experimentally via pharmacological reductions in heart rate, heart and lung transplantation, upper airways anaesthesia, and spinal blockade of sensory stimuli from the working muscles do not show any significant reduction in perception of effort [71]. On the contrary, a recent study has demonstrated a significant correlation between neurophysiological measures of central motor command (motor-related cortical potentials) and perception of effort during exercise [72]. This psychophysiological data suggests that perception of effort is generated by central processing of a corollary discharge reflecting central motor command to the active muscles (corollary discharge model). This model mirrors the conceptual models of pain and dyspnoea, with sensory and affective components interacting together. In fact, a study has shown that while intensity may increase linearly, the affect associated with exercise may worsen nonlinearly [73]. Understanding the normal symptomatic (respiratory, limb fatigue, general exertion) response to exercise is of great psychophysiological interest, but can also provide important information that could better direct pathophysiological research. However, the interactions between respiratory symptoms, limb muscle fatigue and general exertion in healthy subjects has not been extensively studied and further research is therefore needed to better understand these interactions.

In patients with respiratory [20] and cardiovascular [74-76] diseases, respiratory limitation during exercise is often encountered, although limb muscle fatigue may also play an important role in exercise limitation $[77,78]$. Whether the respective role of dyspnoea and limb muscle fatigue may be influenced by the testing modality is still debated [79]. When compared to aged-matched controls, dyspnoea in patients with cardiorespiratory diseases is significantly increased for a given level of work rate, oxygen uptake and minute ventilation (fig. 1) [20]. This is the result of a mismatch between the outgoing motor command and the mechanical/muscular response of the respiratory system [20]. This disparity, termed "neuro-mechanical dissociation" is operationalised through the ventilation to maximal ventilatory capacity ratio, the inspiratory effort (tidal oesophageal pressure) relative to maximum or the inspiratory effort relative to tidal volume displacement (effort-volume displacement ratio). In these patients, dyspnoea is also qualitatively 

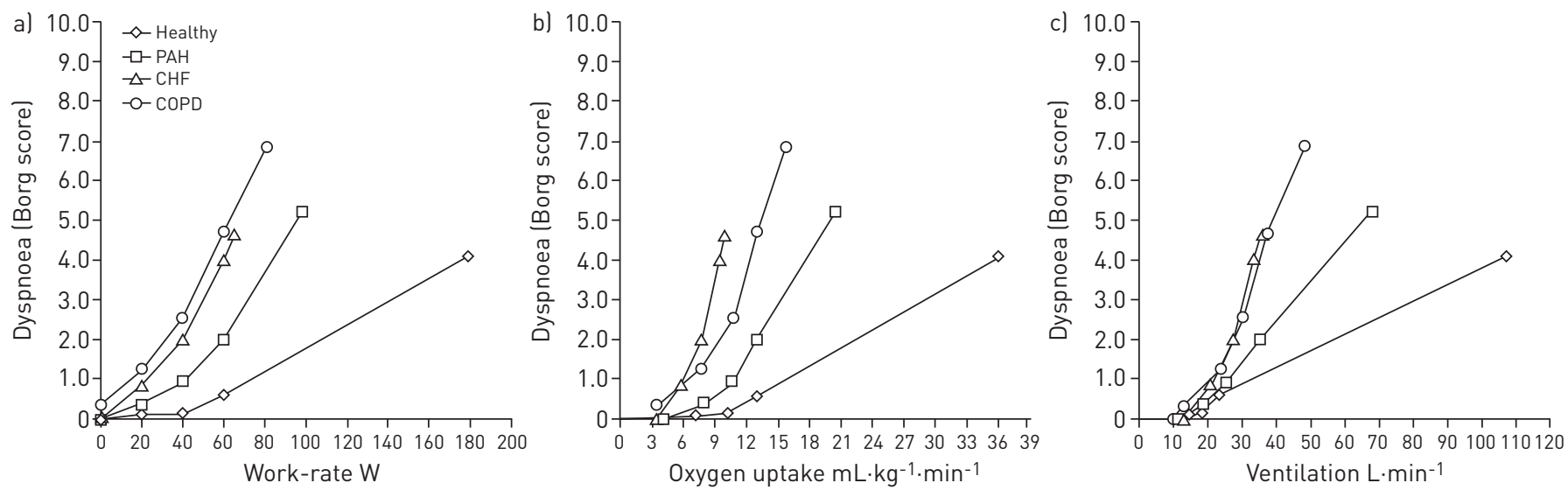

FIGURE 1 Exertional dyspnoea intensity (Borg score) is shown in response to increasing a) work rate, b) oxygen uptake and c) minute ventilation during symptom-limited incremental cycle exercise in a healthy subject, in a patient with chronic obstructive pulmonary disease (COPD), in a patient with pulmonary arterial hypertension $(\mathrm{PAH})$ and in a patient with chronic heart failure (CHF). Data from the authors' laboratory in Paris, France.

different from aged-matched controls; for example, COPD and interstitial lung disease (ILD) patients report more "unsatisfied inspiration" and "inspiratory difficulty" than controls [17, 80]. Patients with chronic heart failure [74], asthma [81,82] and pulmonary arterial hypertension [76] also suffer from significant exertional dyspnoea. The majority of these patients complain of exertional dyspnoea similar to that of COPD patients, which results from the inability of tidal volume to expand appropriately as ventilation increases because it is constrained: 1 ) from below by the effects of dynamic lung hyperinflation in COPD [83], and in selected patients with asthma [81, 82], chronic heart failure [74], ILD [75, 80, 84, 85] and pulmonary arterial hypertension [76], or by the already critically reduced resting inspiratory capacity in COPD [86]; or 2) from above (reflecting the reduced total lung capacity and inspiratory reserve volume, as may occur in some patients with chronic heart failure, ILD and pulmonary arterial hypertension).

In COPD and selected patients with asthma, once tidal volume has plateaued and further expansion is negated (i.e. there is simply "no more space to breathe"), the effort-volume displacement ratio increases sharply with a simultaneous steep increase in dyspnoea intensity and a change in its quality to "unsatisfied inspiration" $[82,87]$.

Patients with COPD and heart failure have very limited exercise tolerance and while dyspnoea is an important limiting symptom, limb muscle discomfort is also an important contributor, at least when the testing modality is cycling exercise. In fact, up to $74 \%$ of patients with COPD report leg fatigue as an important limiting factor, either alone or in combination with dyspnoea [88]. There is now clear evidence that COPD [78, 89, 90] and heart failure [89] have consequences on limb muscle biology that could precipitate fatigue. While the vastus lateralis is usually studied, other leg muscles have been shown to be more prone to fatigue, in patients with COPD at least [91]. Its interaction with dyspnoea is, however, not clear, and how these two sensations interact to regulate exercise tolerance is of great importance. For example, studies have shown that patients who develop contractile limb muscle fatigue during a cycle exercise test have less improvement with bronchodilation than patients who are ventilatory limited [92]. In a recent study, afferents from the lower limbs were blocked in patients with COPD by selective spinal anaesthesia [93]. Compared to a placebo condition, peak ventilation and dyspnoea for a given level of ventilation were reduced, resulting in improved exercise tolerance. These results suggest that extrapulmonary targets of treatment could potentially alleviate dyspnoea in these patients.

\section{The clinical impact and management of dyspnoea}

Because a significant part of lung, vascular or cardiac damage is often irreversible in chronic cardiorespiratory diseases, dyspnoea, as a symptom, becomes an important target, especially in light of its deleterious consequences. However, effective relief of chronic dyspnoea remains one of the most challenging goals of management in patients with advanced cardiopulmonary disease [2]. Traditionally, the approach to improving dyspnoea in all of the major cardiopulmonary diseases involves interventions that: 1) reduce the ventilatory demand (by reducing the drive to breathe);2) improve ventilatory capacity; 3) improve respiratory mechanics or respiratory muscle function; 4) address the affective dimension of dyspnoea; or 5) any combination of the above. 
It is of note that interventions should be selected based on the underlying pathophysiological background of the specific disease and may therefore differ from one disease to another. Multiple interventions are generally required and appear to have additive or synergistic effects [94, 95]. Some of these interventions include: bronchodilators, oxygen, heliox, exercise training, biventricular pacing (specific for selected chronic heart failure patients), biofeedback techniques, non-invasive ventilation, lung volume reduction surgery and related endoscopic techniques, and various combinations of these. All of the above strategies have proven to provide beneficial sensory consequences in a variety of patients with cardiopulmonary diseases [96-100]. In selected patients with COPD and chronic heart failure, interventions such as opiates (oral and inhaled) reduce respiratory drive and alter affective components of dyspnoea [101-105] and may increase exercise tolerance [106]. Inhaled furosemide could also be a treatment avenue in certain populations [107-109]. Recently, it has been shown that inhaled furosemide may modulate respiratory sensation by altering afferent inputs from vagal receptors within the lungs in patients with COPD [110]. Psychological counselling, cognitive/behavioural modification and anxiolytics [111] may also have favourable influences on the affective dimension of chronic dyspnoea, but additional research is needed [104]. Cardiac or pulmonary rehabilitation is also an important component of dyspnoea management, which incorporates exercise training, self-management education and psychosocial interventions [112]. In COPD, exercise training improves limb muscle function [113] and biochemistry [114], which results in reduced ventilatory requirements with concurrent reduction in tidal volume expansion constraints. These improvements can explain and motivate the inclusion of exercise training programmes in patients whose inherent cardiovascular function cannot be improved, which is usually the case in most chronic cardiorespiratory diseases. Further, targeted training of inspiratory muscles may increase their strength and endurance in COPD [115, 116], chronic heart failure [117, 118] and asthma [119]. Again, the net effect is improved neuromechanical coupling of the respiratory system. Pulmonary rehabilitation also improves the cognitive and affective dimensions of chronic dyspnoea [120-123], which, for many severe patients, is the dominant effect of this intervention.

In addition to having limited success in alleviating dyspnoea in its various presentations, the understanding of the central mechanisms of dyspnoea relief is, at best, poor. It is important to consider that dyspnoea relief (i.e. its removal or mitigation) is more than the reduction in negative sensation; an important component of dyspnoea relief is the rewarding and positive sensation of "pleasantness" that accompanies it [124-127]. Relief can act at the level of sensorimotor integration and/or at a central level [18]. At the sensorimotor level, a reduction in neuromechanical dissociation, through a decrease of outgoing command and/or improvement of effectors function and/or a reduction of afferent activity is usually the focus of most targeted interventions. As discussed above, relief can also be induced by a modulating action at the central level on perception per se, through either the context (affective-cognitive, social and/or cultural factors) and/or on immediate (emotional) and/or secondary, more sophisticated (cognitive-behavioural) reactions to dyspnoea. It is important to consider, however, that these observations have yet to be reproduced in clinical settings.

When breathing is unconscious, it is devoid of affectivity. Relief of dyspnoea represents an occurrence of breathing becoming pleasant and rewarding, not merely absence of unpleasantness. These positive responses of dyspnoea relief are associated with patterns of brain activation not unlike those induced by pleasant sensations. Brain imaging techniques have shown that relief of pain [128-130] or thirst [131, 132] is associated with a reduction of activity in areas involved in the perception of these sensations as well as the activation of structures that seem linked to their relief. A single published study has addressed brain activation patterns associated with the relief of dyspnoea [125]. It shows a reduction in the activation of brain regions activated during high levels of dyspnoea, along with activation of other, relief-specific regions, notably the left anterior cingulate cortex, the posterior cerebellum, the temporal and prefrontal cortices and the midbrain [125]. Therefore, it would seem that dyspnoea relief is the combination of a decrease in dyspnoea-activated brain regions combined to the activation of regions specific to its relief. These emerging results suggest that dyspnoea relief is primarily a decrease in dyspnoea intensity and they support the view that it is a more complex sensory/emotional experience, involving a characteristic central processing and that it may be involved in dyspnoea modulation. These pleasant respiratory sensations could play an adaptive role by adding an additional drive in a deleterious breathing situation.

\section{Dyspnoea mechanisms and relief in specific conditions}

Dyspnoea is a prevalent symptom in many cardiorespiratory health conditions. Some manifestations of this symptom are less known and present a challenge, whether in identifying the underlying mechanisms or measuring its impact on patients.

Patients suffering from idiopathic hyperventilation report shortness of breath, dizziness and chest tightness, along with increased anxiety and depression and general poor health status. The few studies in these patients 
have shown that central chemosensitivity appears normal and that peripheral chemoreceptor response is suppressed, but can be normalised with increased end-tidal partial pressure of carbon dioxide [133-136]. The ventilatory response to moderate intensity exercise is appropriate for the reduced partial pressure of carbon dioxide set point and breath holding time is markedly short, suggestive of an additional sustained component of ventilatory drive that also appears to operate throughout exercise. Dyspnoea in these patients may reflect an inappropriate cortical processing of respiratory-related sensory inputs [137].

Respiratory discomfort may be a significant issue in intensive care unit (ICU) patients in general and mechanically ventilated ones in particular. In the few studies addressing this question, dyspnoea has been reported in almost $50 \%$ of patients [138]. A stay in the ICU may also be associated with significant and long-lasting distress; two-thirds of patients remembered their stay in the ICU associated with negative affect and post-traumatic stress [139]. In fact, memories of "suffocation" were the second most reported complaint after a stay in the ICU [140]. Things could get worse in the future, as current ICU management trends are designed to reduce iatrogenic complications and shorten ICU stay. With this aim, prominent measures include reducing tidal volume whatever the indication of mechanical ventilation [117], reducing sedation [141], and preserving inspiratory activity, even in the presence of severe gas exchange alterations [142]. These strategies carry the risk of exposing patients to dyspnoea, possibly extreme, during mechanical ventilation. Yet current treatment guidelines do not focus on symptoms, but rather on more easily measurable outcomes [143]. However, optimal management in the ICU should not discount dyspnoea as inevitable and unimportant. Healthcare providers in this setting should be sensitised to this symptom and further research will be needed to maximise care for patients in the ICU in order to maximise survival and minimise discomfort.

\section{Conclusions and perspectives}

Dyspnoea is a multifactorial symptom, involving the interaction between various physiological, psychological and environmental factors. Its understanding may only derive from a multidisciplinary and multidimensional approach.

While significant progress has been made, there remain several unanswered questions on the neurophysiology of dyspnoea. First, the mechanisms of the gating process of respiratory sensations remain unclear (for example, does the gating process differ between patients with chronic dyspnoea, healthy sedentary and athletes?) and a better understanding of its determinants could offer insights onto novel therapeutic avenues. Secondly, the neurophysiological processing of these sensations still holds some questions, as the different types of dyspnoea seem to involve different physiological pathways. Current models hypothesise that an imbalance between inspiratory activation (drive) and afferent signal underlies some sensations of dyspnoea, and different origins of corollary discharges may also contribute to the different sensations $[2,15,20,144]$. However, possible exception to that general characterisation may be sensations of "tightness" which probably arise fairly directly from vagally mediated afferents associated with bronchoconstriction $[145,146]$, i.e. not so much due to efferent-afferent imbalance, although the corollary discharge model likely accounts for sensations of effort that often accompany tightness [147, 148].

Additional research to further understand the different types of dyspnoea and their mechanisms could also lead to interventions that specifically target the relevant dyspnoeic sensations in patients. In addition, as sensory information alone does not generate dyspnoea, a better understanding of the affective and threat components of dyspnoea, specifically how the affective state affects the unpleasant aspects of dyspnoea and how unpleasant respiratory sensations become threatening could improve it treatment. Figure 2 sums up an updated model of dyspnoea that incorporates limbic system (affective) involvement. Finally, there is still an enormous amount of work to be done in developing proper measurement tools for dyspnoea. While progress has been made, with the development of dyspnoea scales that incorporate the affective dimensions [24,55-58], there is still room for a better understanding of the language of dyspnoea (for example, similarities and discrepancies between qualitative descriptors of dyspnoea such as "air hunger" and "unsatisfied inspiration" in cardiorespiratory diseases) and how it can help identify the underlying physiological processes. Other studies in languages other than English are also needed as expression of dyspnoea may vary; for example, air hunger dyspnoea is translated in French as "soif d'air" or "air thirst" [149]. These differences might help us improve our understanding of how healthy subjects and patients express dyspnoea.

In healthy individuals, the neurophysiology and affective processing of respiratory sensations has barely been studied. Additional research in this area could lead to a better understanding of how intense recruitment of the respiratory system can lead to intense respiratory sensations that are not distressing, and sometimes even pleasant in athletes [150]. A unified understanding of how respiratory sensations and other exertional symptoms, like limb muscle fatigue and general exertion, interact in relationship with fitness 
FIGURE 2 Integrative mechanisms of dyspnoea. Respiratory muscle action is the result of the integration, at the level of the spinal motoneurones, of motor commands from the medulla and the motor cortex. The resulting activation of respiratory effectors produces afferent feedback, which is transmitted to the motor command sources and the somatosensory cortex. At this point, the comparison between the corollary discharge (a copy of the motor command sent to the somatosensory cortex) and the resulting afferent feedback may result in a mismatch (sensory component). Dyspnoea will occur when negative affects from the limbic cortex are attributed to this sensory mismatch (affective component). Different corollary discharges and afferent feedback may result in different types of dyspnoea. In addition, the affective component of dyspnoea will implicate a complex interaction between, notably, past experience (memory) and the environment.

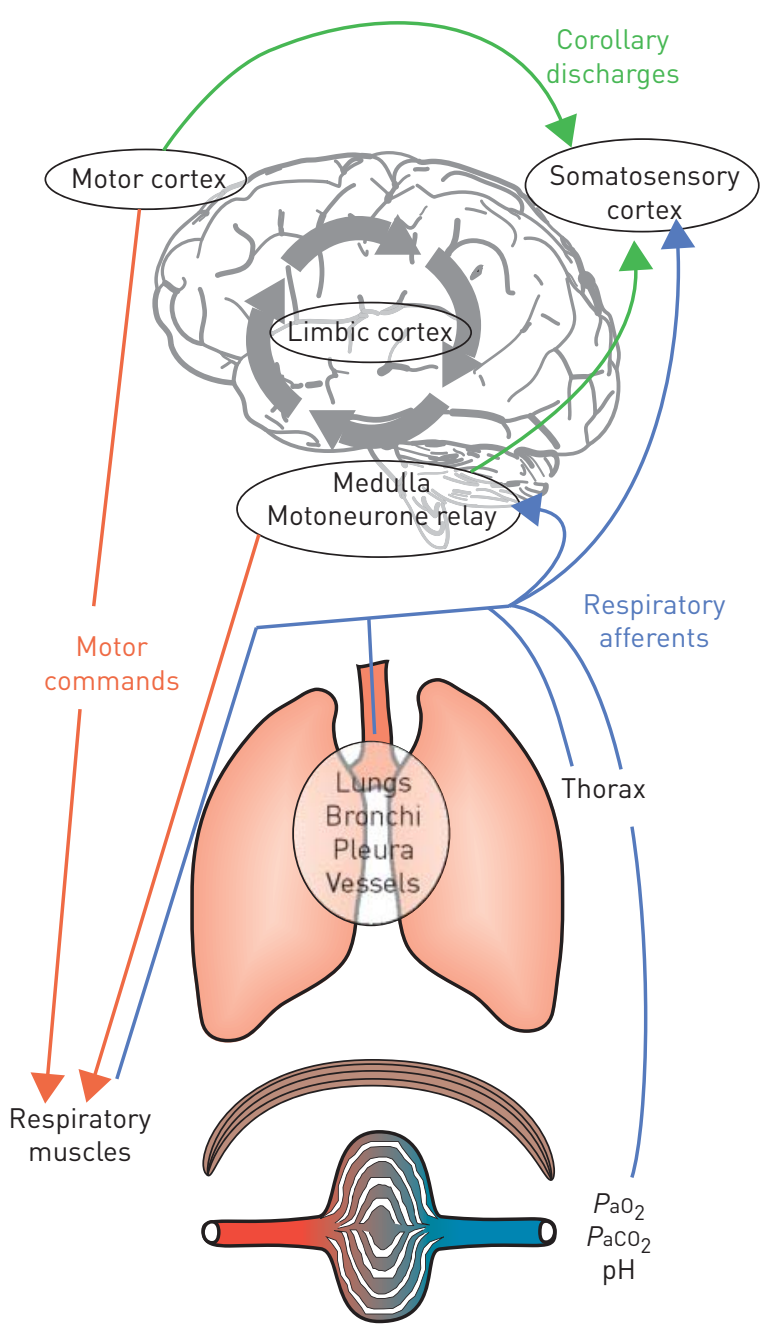

level, exercise modality and exercise protocol would also potentially benefit our understanding of the mechanisms of these symptoms and how they interact in normal physiology. These findings could also improve our understanding of the processes involved in the efficacy of exercise training in patients with chronic dyspnoea, and enable us to optimise the training parameters.

In patients, while the physiological mechanisms of dyspnoea are well studied, a better understanding of the sometimes unconvincing link between pathophysiological impairment and symptoms could potentially improve the lukewarm success of the treatment of dyspnoea.

Finally, the research on dyspnoea relief is still at an embryonic stage. Additional research on its neurophysiological mechanisms in clinical populations would be useful in better characterising it. In the future, this research points to hypothetical treatment avenues that could act on downstream neurophysiological processes of dyspnoea and potentially help in improving the efficiency of existing treatments. Also, studies on the mechanisms and characteristics of dyspnoea in understudied conditions, such as pulmonary hypertension and idiopathic hyperventilation, and settings, such as the ICU, are warranted.

The consensus of the group was that, despite the significant increase in the understanding of the mechanisms of dyspnoea, there have been limited improvements in its treatment during the past decade. Dyspnoea is already an important cause of morbidity, in both prevalence and impact [3-5], that may very well worsen due to the increasing burden of chronic diseases associated with dyspnoea [151]. As such, the continuing effort to better understand its mechanisms and an emphasis on translating this understanding into better treatment options will become even more important. 


\section{Acknowledgements}

The members of the European Respiratory Society research seminar faculty were: P. Laveneziana (co-chair; Paris, France), L. Laviolette (co-chair; Paris, France), P.W. Davenport (Gainsville, USA), R.B. Banzett (Boston, USA), A. Von Leupoldt (Hamburg, Germany), M.B. Parshall (Albuquerque, USA), S. Marcora (Kent, UK), L. Romer (Uxbridge, UK), D.E. O’Donnell (Kingston, Canada), F. Maltais (Quebec, Canada), C. Peiffer (Paris, France), C. Morelot-Panzini (Paris, France), S. Jack (Liverpool, UK), and T. Similowski (Paris, France).

The participants in the European Respiratory Society research seminar were: E. Allard (France), J.J. Benoliel (France), V. Bougault (France), P. Cejudo (Spain), M. Chavez (France), C. Chenivesse (France), S. Chikina (Russia), C. Delclaux (France), A. Edvardsen (Norway), G. Fabris (UK), G. Garcia (France), P. Hernandez (Canada), A. Hudson (France), M. Jabbour (Lebanon), T. Janssens (Belgium), B. Joureau (France), H.J. Kabitz (Germany), C. Karachi (France), J. Martinerie (France), L. Naccache (France), K. Neumannova (Czech Republic), H. Neveu (France), M.C. Nierat (France), S. Pieroni (Italy), P. Piirilä (Finland), C. Pilar (Spain), P. Pouget (France), M. Raux (France), S. Simons (The Netherlands), C. Spengler (Switzerland), R. Stanciu (UK), C. Straus (France), M. Teulier (France), J. Varga (Hungary), M. Van Den Berg (The Netherlands), F. Vermeulen (Belgium), and Agnès Bellocq (France). V. Rebeaud and L. Monnot were also present as European Respiratory Society scientific activities assistants.

\section{References}

1 American Thoracic Society. Dyspnea. Mechanisms, assessment and management: a consensus statement. Am J Respir Crit Care Med. 1999; 159: 321-340.

2 Parshall M, Schwartzstein R, Adams L, et al. Update of an official ATS statement: mechanisms, assessment, and management of dyspnea. Am J Respir Crit Care Med 2012; 185: 435-452.

3 Desbiens N, Mueller-Rizner N, Connors A, et al. The relationship of nausea and dyspnea to pain in seriously ill patients. Pain 1997; 71: 149-156.

4 Hammond E. Some preliminerary findings on the physical complaints from a prospective study of 1,064,004 men and women. Am J Public Health Nations Health 1964; 54: 11-23.

5 Kroenke K, Arrington M, Mangelsdorff A. The prevalence of symptoms in medical outpatients and the adequacy of therapy. Arch Intern Med 1990; 150: 1685-1689.

6 Currow D, Plummer J, Crockett A, et al. A community population survey of prevalence and severity of dyspnea in adults. J Pain Symptom Manage 2009; 38: 533-545.

7 Grønseth R, Vollmer WM, Hardie JA, et al. Predictors of dyspnoea prevalence: results from the BOLD study. Eur Respir J 2014; 43: 1610-1620.

8 Nishimura K, Izumi T, Tsukino M, et al. Dyspnea is a better predictor of 5-year survival than airway obstruction in patients with COPD. Chest 2002; 121: 1434-1440.

9 Abidov A, Rozanski A, Hachamovitch R, et al. Prognostic significance of dyspnea in patients referred for cardiac stress testing. N Engl J Med 2005; 353: 1889-1898.

10 Ho S, O’Mahony MS, Steward J, et al. Dyspnoea and quality of life in older people at home. Age Ageing 2001; 30: 155-159.

11 Perri M, Anton S, Durning P, et al. Adherence to exercise prescriptions: effects of prescribing moderate versus higher levels of intensity and frequency. Health Psychol 2002; 21: 452-458.

12 Hayton C, Clark A, Olive S, et al. Barriers to pulmonary rehabilitation: characteristics that predict patient attendance and adherence. Respir Med 2013; 107: 401-407.

13 Cromwell H, Mears R, Wan L, et al. Sensory gating: a translational effort from basic to clinical science. Clin EEG Neurosci 2008; 39: 69-72.

14 Venables P. Input dysfunction in schizophrenia. Prog Exp Pers Res 1964; 72: 1-47.

15 Davenport P, Vovk A. Cortical and subcortical central neural pathways in respiratory sensations. Respir Physiol Neurobiol 2009; 167: 72-86.

16 Banzett R, Lansing R, Reid $\mathrm{M}$, et al. 'Air hunger' arising from increased $P_{\mathrm{CO}_{2}}$ in mechanically ventilated quadriplegics. Respir Physiol 1989; 76: 53-67.

17 O’Donnell DE, Bertley J, Chau L, et al. Qualitative aspects of exertional breathlessness in chronic airflow limitation: pathophysiologic mechanisms. Am J Respir Crit Care Med 1997; 155: 109-115.

18 Lansing R, Gracely R, Banzett R. The multiple dimensions of dyspnea: review and hypotheses. Respir Physiol Neurobiol 2009; 167: 53-60.

19 El-Manshawi A, Killian K, Summers E, et al. Breathlessness during exercise with and without resistive loading. J Appl Physiol 1986; 61: 896-905.

20 O’Donnell DE, Ora J, Webb K, et al. Mechanisms of activity-related dyspnea in pulmonary diseases. Respir Physiol Neurobiol 2009; 167: 116-132.

21 Lansing R, Im B, Thwing J, et al. The perception of respiratory work and effort can be independent of the perception of air hunger. Am J Respir Crit Care Med 2000; 162: 1690-1696.

22 Parshall M, Welsh J, Brockopp D, et al. Reliability and validity of dyspnea sensory quality descriptors in heart failure patients treated in an emergency department. Heart Lung 2001; 30: 57-65.

23 Parshall M. Psychometric characteristics of dyspnea descriptor ratings in emergency department patients with exacerbated chronic obstructive pulmonary disease. Res Nurs Health 2002; 25: 331-344.

24 Banzett R, Pedersen S, Schwartzstein R, et al. The affective dimension of laboratory dyspnea: air hunger is more unpleasant than work/effort. Am J Respir Crit Care Med 2008; 177: 1384-1390.

25 Gozal D, Omidvar O, Kirlew K, et al. Identification of human brain regions underlying responses to resistive inspiratory loading with functional magnetic resonance imaging. Proc Natl Acad Sci USA 1995; 92: 6607-6611.

26 Evans K, Banzett R, Adams L, et al. BOLD fMRI identifies limbic, paralimbic, and cerebellar activation during air hunger. J Neurophysiol 2002; 88: 1500-1511.

27 Von Leupoldt A, Sommer T, Kegat S, et al. The unpleasantness of perceived dyspnea is processed in the anterior insula and amygdala. Am J Respir Crit Care Med 2008; 177: 1026-1032.

28 Evans K. Cortico-limbic circuitry and the airways: insights from functional neuroimaging of respiratory afferents and efferents. Biol Psychol 2010; 84: 13-25. 
29 Paulus M, Flagan T, Simmons A, et al. Subjecting elite athletes to inspiratory breathing load reveals behavioral and neural signatures of optimal performers in extreme environments. PLoS ONE 2012; 7: e29394.

30 Wilson R, Jones P. Differentiation between the intensity of breathlessness and the distress it evokes in normal subjects during exercise. Clin Sci (Lond) 1991; 80: 65-70.

31 Von Leupoldt A, Dahme B. Differentiation between the sensory and affective dimension of dyspnea during resistive load breathing in normal subjects. Chest 2005; 128: 3345-3349.

32 Lehrer P, Hochron S, Isenberg S, et al. The asthma symptom profile: a psychophysically based scale for assessment of asthma symptoms. J Psychosom Res 1993; 37: 515-521.

33 Von Leupoldt A, Mertz C, Kegat S, et al. The impact of emotions on the sensory and affective dimension of perceived dyspnea. Psychophysiology 2006; 43: 382-386.

34 Rietveld S, Van Beest I. Rollercoaster asthma: when positive emotional stress interferes with dyspnea perception. Behav Res Ther 2007; 45: 977-987.

35 Von Leupoldt A, Dahme B. The impact of emotions on symptom perception in patients with asthma and healthy controls. Psychophysiology 2013; 50: 1-4.

36 Von Leupoldt A, Chan P, Esser R, et al. Emotions and neural processing of respiratory sensations investigated with respiratory-related evoked potentials. Psychosom Med 2013; 75: 244-252.

37 Von Leupoldt A, Taube K, Schubert-Heukeshoven S, et al. Distractive auditory stimuli reduce the unpleasantness of dyspnea during exercise in patients with COPD. Chest 2007; 132: 1506-1512.

38 Harter M, Conway K, Merikangas K. Associations between anxiety disorders and physical illness. Eur Arch Psychiatry Clin Neurosci 2003; 253: 313-320.

39 Livermore N, Butler J, Sharpe L, et al. Panic attacks and perception of inspiratory resistive loads in chronic obstructive pulmonary disease. Am J Respir Crit Care Med 2008; 178: 7-12.

40 Chan P, Von Leupoldt A, Bradley M, et al. The effect of anxiety on respiratory sensory gating measured by respiratory-related evoked potentials. Biol Psychol 2012; 91: 185-189.

41 Ritz T, Meuret AE, Trueba AF, et al. Psychosocial factors and behavioral medicine interventions in asthma. J Consult Clin Psychol 2013; 81: 231-250.

42 Papaioannou A, Bartziokas K, Tsikrika S, et al. The impact of depressive symptoms on recovery and outcome of hospitalised COPD exacerbations. Eur Respir J 2013; 41: 815-823.

43 Chida Y, Hamer M, Steptoe A. A bidirectional relationship between psychosocial factors and atopic disorders: a systematic review and meta-analysis. Psychosom Med 2008; 70: 102-116.

44 Douwes J, Brooks C, Pearce N. Asthma nervosa: old concept, new insights. Eur Respir J 2011; 37: 986-990.

45 Goodwin R, Jacobi F, Thefeld W. Mental disorders and asthma in the community. Arch Gen Psychiatry 2003; 60: $1125-1130$.

46 Katon W, Richardson L, Russo J, et al. Quality of mental health care for youth with asthma and comorbid anxiety and depression. Med Care 2006; 44: 1064-1072.

47 Maurer J, Rebbapragada V, Borson S, et al. Anxiety and depression in COPD: current understanding, unanswered questions, and research needs. Chest 2008; 134: 43S-56S.

48 Vogele C, Von Leupoldt A. Mental disorders in chronic obstructive pulmonary disease (COPD). Respir Med 2008; 102: 764-773.

49 Comroe J. Dyspnea. Mod Concepts Cardiovasc Dis 1956; 25: 347-349.

50 Melzack R, Torgerson W. On the language of pain. Anesthesiology 1971; 34: 50-59.

51 Simon P, Schwartzstein R, Weiss J, et al. Distinguishable types of dyspnea in patients with shortness of breath. Am Rev Respir Dis 1990; 142: 1009-1014.

52 Simon P, Schwartzstein R, Weiss J, et al. Distinguishable sensations of breathlessness induced in normal volunteers. Am Rev Respir Dis 1989; 140: 1021-1027.

53 Elliott M, Adams L, Cockcroft A, et al. The language of breathlessness. Use of verbal descriptors by patients with cardiopulmonary disease. Am Rev Respir Dis 1991; 144: 826-832.

54 Mahler D, Harver A, Lentine T, et al. Descriptors of breathlessness in cardiorespiratory diseases. Am J Respir Crit Care Med 1996; 154: 1357-1363.

55 Parshall M, Carle A, Ice U, et al. Validation of a three-factor measurement model of dyspnea in hospitalized adults with heart failure. Heart Lung 2012; 41: 44-56.

56 Meek P, Banzett R, Parshall M, et al. Reliability and validity of the multidimensional dyspnea profile. Chest 2012; 141: 1546-1553.

57 Yorke J, Moosavi S, Shuldham C, et al. Quantification of dyspnoea using descriptors: development and initial testing of the dyspnoea-12. Thorax 2010; 65: 21-26.

58 Yorke J, Russell A, Swigris J, et al. Assessment of dyspnea in asthma: validation of the dyspnea-12. J Asthma 2011; 48: 602-608.

59 Williams M, Cafarella P, Olds T, et al. The language of breathlessness differentiates between patients with COPD and age-matched adults. Chest 2008; 134: 489-496.

60 Smith J, Albert P, Bertella E, et al. Qualitative aspects of breathlessness in health and disease. Thorax 2009; 64: 713-718.

61 Wilcock A, Crosby V, Hughes A, et al. Descriptors of breathlessness in patients with cancer and other cardiorespiratory diseases. J Pain Symptom Manage 2002; 23: 182-189.

62 Wasserman K, Hansen JE, Sue DY, et al. Principles of Exercise Testing and Interpretation: Including Pathophysiology and Clinical Applications. Philadelphia, Lippincott Williams \& Wilkins, 2004.

63 Dempsey JJB. Wolffe memorial lecture. Is the lung built for exercise? Med Sci Sports Exerc 1986; 18: 143-155.

64 Hamilton A, Killian K, Summers E, et al. Quantification of intensity of sensations during muscular work by normal subjects. J Appl Physiol 1996; 81: 1156-1161.

65 Jones N, Killian K. Exercise limitation in health and disease. N Engl J Med 2000; 343: 632-641.

66 Borg E, Borg G, Larsson K, et al. An index for breathlessness and leg fatigue. Scand J Med Sci Sports 2010; 20: 644-650.

67 Green J, Crews T, Bosak A, et al. Overall and differentiated ratings of perceived exertion at the respiratory compensation threshold: effects of gender and mode. Eur J Appl Physiol 2003; 89: 445-450. 
Jensen D, Ofir D, O'Donnell DE. Effects of pregnancy, obesity and aging on the intensity of perceived breathlessness during exercise in healthy humans. Respir Physiol Neurobiol 2009; 167: 87-100.

69 Marcora SM. Effort: Perception Of. In: Goldstein BE, ed. Encyclopedia of Perception. Los Angeles, Sage, 2010; pp. 380-383.

70 St Clair Gibson A, Lambert E, Rauch L, et al. The role of information processing between the brain and peripheral physiological systems in pacing and perception of effort. Sports Med 2006; 36: 705-722.

71 Marcora S. Perception of effort during exercise is independent of afferent feedback from skeletal muscles, heart, and lungs. J Appl Physiol 2009; 106: 2060-2062.

72 De Morree HM, Klein C, Marcora S. Perception of effort reflects central motor command during movement execution. Psychophysiology 2012; 49: 1242-1253.

73 Ekkekakis P, Hall E, Petruzzello S. Practical markers of the transition from aerobic to anaerobic metabolism during exercise: rationale and a case for affect-based exercise prescription. Prev Med 2004; 38: 149-159.

74 Laveneziana P, O'Donnell DE, Ofir D, et al. Effect of biventricular pacing on ventilatory and perceptual responses to exercise in patients with stable chronic heart failure. J Appl Physiol 2009; 106: 1574-1583.

75 Cross T, Sabapathy S, Beck K, et al. The resistive and elastic work of breathing during exercise in patients with chronic heart failure. Eur Respir J 2012; 39: 1449-1457.

76 Laveneziana P, Garcia G, Joureau B, et al. Dynamic respiratory mechanics and exertional dyspnoea in pulmonary arterial hypertension. Eur Respir J 2013; 41: 578-587.

77 Hamilton A, Killian K, Summers E, et al. Symptom intensity and subjective limitation to exercise in patients with cardiorespiratory disorders. Chest 1996; 110: 1255-1263.

78 Skeletal muscle dysfunction in chronic obstructive pulmonary disease. A statement of the American Thoracic Society and European Respiratory Society. Am J Respir Crit Care Med. 1999; 159: S1-S40.

79 Pepin V, Saey D, Whittom F, et al. Walking versus cycling: sensitivity to bronchodilation in chronic obstructive pulmonary disease. Am J Respir Crit Care Med 2005; 172: 1517-1522.

80 O'Donnell DE, Chau LK, Webb KA. Qualitative aspects of exertional dyspnea in patients with interstitial lung disease. J Appl Physiol 1998; 84: 2000-2009.

81 Laveneziana P, Lotti P, Coli C, et al. Mechanisms of dyspnoea and its language in patients with asthma. Eur Respir J 2006; 27: 742-747.

82 Laveneziana P, Bruni G, Presi I, et al. Tidal volume inflection and its sensory consequences during exercise in patients with stable asthma. Respir Physiol Neurobiol 2013; 185: 374-379.

83 O’Donnell DE, Travers J, Webb K, et al. Reliability of ventilatory parameters during cycle ergometry in multicentre trials in COPD. Eur Respir J 2009; 34: 866-874.

84 Marciniuk D, Sridhar G, Clemens R, et al. Lung volumes and expiratory flow limitation during exercise in interstitial lung disease. J Appl Physiol 1994; 77: 963-973.

85 Walterspacher S, Schlager D, Walker D, et al. Respiratory muscle function in interstitial lung disease. Eur Respir J 2013; 42: 211-219.

86 Guenette J, Webb K, O’Donnell DE. Does dynamic hyperinflation contribute to dyspnoea during exercise in patients with COPD? Eur Respir J 2012; 40: 322-329.

87 Laveneziana P, Webb KA, Ora J, et al. Evolution of dyspnea during exercise in chronic obstructive pulmonary disease: impact of critical volume constraints. Am J Respir Crit Care Med 2011; 184: 1367-1373.

88 Killian K, Leblanc P, Martin D, et al. Exercise capacity and ventilatory, circulatory, and symptom limitation in patients with chronic airflow limitation. Am Rev Respir Dis 1992; 146: 935-940.

89 Gosker H, Wouters E, Van Der Vusse GJ, et al. Skeletal muscle dysfunction in chronic obstructive pulmonary disease and chronic heart failure: underlying mechanisms and therapy perspectives. Am J Clin Nutr 2000; 71: 1033-1047.

90 Maltais F, Sullivan M, Leblanc P, et al. Altered expression of myosin heavy chain in the vastus lateralis muscle in patients with COPD. Eur Respir J 1999; 13: 850-854.

91 Gagnon P, Maltais F, Bouyer L, et al. Distal leg muscle function in patients with COPD. COPD 2013; 10: $235-242$.

92 Saey D, Debigare R, Leblanc P, et al. Contractile leg fatigue after cycle exercise: a factor limiting exercise in patients with chronic obstructive pulmonary disease. Am J Respir Crit Care Med 2003; 168: 425-430.

93 Gagnon P, Bussieres JS, Ribeiro F, et al. Influences of spinal anesthesia on exercise tolerance in patients with chronic obstructive pulmonary disease. Am J Respir Crit Care Med 2012; 186: 606-615.

94 Peters M, Webb K, O’Donnell DE. Combined physiological effects of bronchodilators and hyperoxia on exertional dyspnoea in normoxic COPD. Thorax 2006; 61: 559-567.

95 Pepin V, Laviolette L, Saey D, et al. Synergetic interactions between rehabilitation and pharmacotherapy in COPD. Clin Invest Med 2006; 29: 170-177.

96 Global Strategy for the Diagnosis, Management and Prevention of COPD, Global Initiative for Chronic Obstructive Lung Disease (GOLD) 2013. Available from: http://www.goldcopd.org/

97 Hunt S, Abraham W, Chin M, et al. ACC/AHA 2005 guideline update for the diagnosis and management of chronic heart failure in the adult: a report of the American College of Cardiology/American Heart Association task force on practice guidelines (writing committee to update the 2001 guidelines for the evaluation and management of heart failure): developed in collaboration with the American College of Chest Physicians and the International Society for Heart and Lung Transplantation: endorsed by the Heart Rhythm Society. Circulation 2005; 112: e154-e235.

98 Celli B, Macnee W. Standards for the diagnosis and treatment of patients with COPD: A summary of the ATS/ERS position paper. Eur Respir J 2004; 23: 932-946.

99 Reddel H, Taylor D, Bateman E, et al. An official American Thoracic Society/European Respiratory Society statement: asthma control and exacerbations: standardizing endpoints for clinical asthma trials and clinical practice. Am J Respir Crit Care Med 2009; 180: 59-99.

100 Mahler D, Decramer M, D’Urzo A, et al. Dual bronchodilation with QVA149 reduces patient-reported dyspnoea in COPD: the BLAZE study. Eur Respir J 2014; 43: 1599-1609.

101 Jennings A, Davies A, Higgins J, et al. A systematic review of the use of opioids in the management of dyspnoea. Thorax 2002; 57: 939-944.

102 Mahler D, Selecky P, Harrod C, et al. American College of Chest Physicians consensus statement on the management of dyspnea in patients with advanced lung or heart disease. Chest 2010; 137: 674-691. 
103 Qaseem A, Snow V, Shekelle P, et al. Evidence-based interventions to improve the palliative care of pain, dyspnea, and depression at the end of life: a clinical practice guideline from the American College of Physicians. Ann Intern Med 2008; 148: 141-146.

104 Marciniuk D, Goodridge D, Hernandez P, et al. Managing dyspnea in patients with advanced chronic obstructive pulmonary disease: a Canadian Thoracic Society clinical practice guideline. Can Respir J 2011; 18: 69-78.

105 Johnson M, Bland J, Oxberry S, et al. Opioids for chronic refractory breathlessness: patient predictors of beneficial response. Eur Respir J 2013; 42: 758-766.

106 Mahler D, Murray J, Waterman L, et al. Endogenous opioids modify dyspnoea during treadmill exercise in patients with COPD. Eur Respir J 2009; 33: 771-777.

107 Nishino T. Pathophysiology of dyspnea evaluated by breath-holding test: studies of furosemide treatment. Respir Physiol Neurobiol 2009; 167: 20-25.

108 Moosavi S, Binks A, Lansing R, et al. Effect of inhaled furosemide on air hunger induced in healthy humans. Respir Physiol Neurobiol 2007; 156: 1-8.

109 Nishino T, Ide T, Sudo T, et al. Inhaled furosemide greatly alleviates the sensation of experimentally induced dyspnea. Am J Respir Crit Care Med 2000; 161: 1963-1967.

110 Jensen D, Amjadi K, Harris-Mcallister V, et al. Mechanisms of dyspnoea relief and improved exercise endurance after furosemide inhalation in COPD. Thorax 2008; 63: 606-613.

111 Lacasse Y, Beaudoin L, Rousseau L, et al. Randomized trial of paroxetine in end-stage COPD. Monaldi Arch Chest Dis 2004; 61: 140-147.

112 Nici L, Donner C, Wouters E, et al. American Thoracic Society/European Respiratory Society statement on pulmonary rehabilitation. Am J Respir Crit Care Med 2006; 173: 1390-1413.

113 Bernard S, Whittom F, Leblanc P, et al. Aerobic and strength training in patients with chronic obstructive pulmonary disease. Am J Respir Crit Care Med 1999; 159: 896-901.

114 Casaburi R, Patessio A, Ioli F, et al. Reductions in exercise lactic acidosis and ventilation as a result of exercise training in patients with obstructive lung disease. Am Rev Respir Dis 1991; 143: 9-18.

115 Hill K, Jenkins S, Philippe D, et al. High-intensity inspiratory muscle training in COPD. Eur Respir J 2006; 27: $1119-1128$.

116 Gosselink R, De Vos J, Van Den Heuvel SP, et al. Impact of inspiratory muscle training in patients with COPD: what is the evidence? Eur Respir J 2011; 37: 416-425.

117 Cahalin L, Arena R, Guazzi M, et al. Inspiratory muscle training in heart disease and heart failure: a review of the literature with a focus on method of training and outcomes. Expert Rev Cardiovasc Ther 2013; 11: 161-177.

118 Marco E, Ramirez-Sarmiento AL, Coloma A, et al. High-intensity vs. sham inspiratory muscle training in patients with chronic heart failure: a prospective randomized trial. Eur J Heart Fail 2013; 15: 892-901.

119 Bruurs M, Van Der Giessen LJ, Moed H. The effectiveness of physiotherapy in patients with asthma: a systematic review of the literature. Respir Med 2013; 107: 483-494.

120 Coventry P. Does pulmonary rehabilitation reduce anxiety and depression in chronic obstructive pulmonary disease? Curr Opin Pulm Med 2009; 15: 143-149.

121 Coventry P, Hind D. Comprehensive pulmonary rehabilitation for anxiety and depression in adults with chronic obstructive pulmonary disease: systematic review and meta-analysis. J Psychosom Res 2007; 63: 551-565.

122 Lacasse Y, Brosseau L, Milne S, et al. Pulmonary rehabilitation for chronic obstructive pulmonary disease. Cochrane Database Syst Rev 2002; CD003793.

123 Ries A, Kaplan R, Limberg T, et al. Effects of pulmonary rehabilitation on physiologic and psychosocial outcomes in patients with chronic obstructive pulmonary disease. Ann Intern Med 1995; 122: 823-832.

124 Nishino T, Isono S, Shinozuka N, et al. Effects of naloxone on respiratory sensation before and after a removal of severe respiratory stress. Jpn J Physiol 2005; 55: 117-126.

125 Peiffer C, Costes N, Herve P, et al. Relief of dyspnea involves a characteristic brain activation and a specific quality of sensation. Am J Respir Crit Care Med 2008; 177: 440-449.

126 Peiffer C. Dyspnea relief: more than just the perception of a decrease in dyspnea. Respir Physiol Neurobiol 2009; 167: 61-71.

127 Nishino T, Ishikawa T, Nozaki-Taguchi N, et al. Lung/chest expansion contributes to generation of pleasantness associated with dyspnoea relief. Respir Physiol Neurobiol 2012; 184: 27-34.

128 Petrovic P, Kalso E, Petersson K, et al. Placebo and opioid analgesia - imaging a shared neuronal network. Science 2002; 295: 1737-1740.

129 Wager T, Rilling J, Smith E, et al. Placebo-induced changes in fMRI in the anticipation and experience of pain. Science 2004; 303: 1162-1167.

130 Willoch F, Gamringer U, Medele R, et al. Analgesia by electrostimulation of the trigeminal ganglion in patients with trigeminopathic pain: a PET activation study. Pain 2003; 103: 119-130.

131 Denton D, Shade R, Zamarippa F, et al. Neuroimaging of genesis and satiation of thirst and an interoceptor-driven theory of origins of primary consciousness. Proc Natl Acad Sci USA 1999; 96: 5304-5309.

132 Parsons L, Denton D, Egan G, et al. Neuroimaging evidence implicating cerebellum in support of sensory/cognitive processes associated with thirst. Proc Natl Acad Sci USA 2000; 97: 2332-2336.

133 Jack S, Rossiter H, Pearson M, et al. Ventilatory responses to inhaled carbon dioxide, hypoxia, and exercise in idiopathic hyperventilation. Am J Respir Crit Care Med 2004; 170: 118-125.

134 Jack S, Rossiter H, Warburton C, et al. Behavioral influences and physiological indices of ventilatory control in subjects with idiopathic hyperventilation. Behav Modif 2003; 27: 637-652.

135 Jack S, Warburton C. A physiological and psychological model of idiopathic hyperventilation. Adv Exp Med Biol 2001; 499: 439-444.

136 Johansen T, Jack S, Dahl R. Normalizing $\mathrm{CO}_{2}$ in chronic hyperventilation by means of a novel breathing mask: a pilot study. Clin Respir J 2013; 7: 359-366.

137 Jack S, Kemp G, Bimson W, et al. Patterns of brain activity in response to respiratory stimulation in patients with idiopathic hyperventilation (IHV). Adv Exp Med Biol 2010; 669: 341-345.

138 Schmidt M, Demoule A, Polito A, et al. Dyspnea in mechanically ventilated critically ill patients. Crit Care Med 2011; 39: 2059-2065. 
139 Rotondi A, Sirio C, Angus D, et al. A new conceptual framework for ICU performance appraisal and improvement. J Crit Care 2002; 17: 16-28.

140 De Miranda S, Pochard F, Chaize M, et al. Postintensive care unit psychological burden in patients with chronic obstructive pulmonary disease and informal caregivers: a multicenter study. Crit Care Med 2011; 39: 112-118.

141 Kress J, Pohlman A, O'Connor MF, et al. Daily interruption of sedative infusions in critically ill patients undergoing mechanical ventilation. N Engl J Med 2000; 342: 1471-1477.

142 Putensen C, Muders T, Varelmann D, et al. The impact of spontaneous breathing during mechanical ventilation. Curr Opin Crit Care 2006; 12: 13-18.

143 Serpa Neto A, Cardoso S, Manetta J, et al. Association between use of lung-protective ventilation with lower tidal volumes and clinical outcomes among patients without acute respiratory distress syndrome: a meta-analysis. JAMA 2012; 308: 1651-1659.

144 O'Donnell DE, Banzett R, Carrieri-Kohlman V, et al. Pathophysiology of dyspnea in chronic obstructive pulmonary disease: a roundtable. Proc Am Thorac Soc 2007; 4: 145-168.

145 Lee L. Respiratory sensations evoked by activation of bronchopulmonary c-fibers. Respir Physiol Neurobiol 2009; 167: $26-35$.

146 Widdicombe J. Lung afferent activity: Implications for respiratory sensation. Respir Physiol Neurobiol 2009; 167: 2-8.

147 Moy M, Lantin M, Harver A, et al. Language of dyspnea in assessment of patients with acute asthma treated with nebulized albuterol. Am J Respir Crit Care Med 1998; 158: 749-753.

148 Moy M, Woodrow Weiss J, Sparrow D, et al. Quality of dyspnea in bronchoconstriction differs from external resistive loads. Am J Respir Crit Care Med 2000; 162: 451-455.

149 Morelot-Panzini C, Demoule A, Straus C, et al. Dyspnea as a noxious sensation: inspiratory threshold loading may trigger diffuse noxious inhibitory controls in humans. J Neurophysiol 2007; 97: 1396-1404.

150 Boecker H, Sprenger T, Spilker M, et al. The runner's high: opioidergic mechanisms in the human brain. Cereb Cortex 2008; 18: 2523-2531.

151 Murray C, Vos T, Lozano R, et al. Disability-adjusted life years (DALYS) for 291 diseases and injuries in 21 regions, 1990-2010: a systematic analysis for the global burden of disease study 2010. Lancet 2012; 380: 2197-2223. 